\title{
Paideia na 'lírica' grega arcaica: a poesia elegíaca e mélica
}

Giuliana Ragusa

Universidade de São Paulo

Rafael Brunhara

Universidade Federal do Rio Grande do Sul

\section{Resumo}

O artigo trata da dimensão paidêutica da "lírica" grega arcaica em dois dos gêneros abarcados nessa designação: elegia e mélica (canção). Naquele, observamos um gênero cuja ocasião de performance prevalente era o simpósio; neste, na modalidade coral, o festival cívico-cultual. Lidamos, pois, com poesia essencialmente oral, que só existe de fato quando apresentada à audiência adequada, formada pela comunidade da polis, em diálogo que pensa, celebra, revalida seus valores e tradições, agregando à essencial função estética a paideia do homem grego. Mostram-no a elegia de Teógnis (Megara) e a canção para coro de virgens de Álcman (Esparta), dois representativos nomes em seus respectivos gêneros.

Palavras-Chaves: Elegia Grega; Mélica Grega; Paideia.

\begin{abstract}
The article discusses the paideutic dimension of the so-called archaic Greek "lyric", namely elegy - a genre designed mainly for performance at the symposium - and melic - a genre for the civic and religious Greek festival. Thus, poetry that is essentially oral, its existence made real when presented to an audience composed by the polis community to which it speaks in a dialogue that reflects on, celebrates and revalidates its values and traditions. By doing so, it conjugates to its essential function (to entertain) the paideia of the Greek man, as shown in the elegy of Theognis (Megara) and in the songs for maidens chorus of Alcman (Sparta), two of the great poets in each of these genres.
\end{abstract}

Keywords: Elegy; Melic; Paideia.

Filosofia e Educação [RFE] - Volume 9, Número 1 - Campinas, SP

Fevereiro-Maio de 2017 - ISSN 1984-9605 - p. 45-62 
A elegia

Teógnis, o aristocrático poeta de Megara (ativo em c. 600 a.C.), assim adverte Cirno, seu amado efebo, aspirante à nobreza: "Eu te

ensinarei boas coisas, como um pai faz a um filho"'. Em um poema, o legislador ateniense Sólon (c. 630-560 a.C.) emoldura as suas lições com um preâmbulo às Musas, filhas de Zeus e Memória, conferindo a graça e a solenidade de um hino aos preceitos entesourados pela tradição; Tirteu de Esparta (ativo em c. 625 a.C.) detalha as virtudes que um bom soldado deve demonstrar.

Todos esses nomes têm um aspecto em comum: foram poetas que veicularam seus ensinamentos e exortações no gênero poético conhecido como elegia.

Hoje, quando falamos em elegia, entendemos poesia de temas tristes em contexto lutuoso. Pode parecer estranho a um leitor do século XXI que os gregos se utilizassem da poesia como meio para educar e aconselhar, e que o fizessem, ainda, em um gênero literário que associamos ao lamento. Entretanto, o modo como esse gênero era concebido em suas origens, no século VII a.C., pode explicar este fenômeno.

Dotada de vasta abrangência temática, dois elementos unificavam a elegia arcaica: metro e performance. $\mathrm{O}$ gênero era identificado pelo critério rítmico, primeiramente: o dístico em que se alternam o hexâmetro dactílico, o metro das célebres epopeias de Homero, e o chamado "pentâmetro", feito da junção de dois hemistíquios predominantemente dactílicos, de maneira que se assemelhava a um hexâmetro ao qual faltaria um pé métrico. ${ }^{2}$

Evidências arqueológicas e documentação literária nos mostraram que o dístico elegíaco se difundiu rapidamente na Grécia, dadas a facilidade de

\footnotetext{
${ }^{1}$ Todas as traduções de fontes primárias e secundárias, salvo quando indicado, são dos autores.

${ }^{2}$ Para uma conceituação mais aprofundada do gênero: West (1974, p. 1-14). Sobre o dístico elegíaco: Adkins (1985, p. 1-33).
}

Filosofia e Educação [RFE] - Volume 9, Número 1 - Campinas, SP

Fevereiro-Maio de 2017 - ISSN 1984-9605 - p. 45-62 
sua apropriação, a regularidade maior que a do hexâmetro épico, e a diversidade menor do que dos metros mélicos. Além disso, combinava sua brevidade com uma natural elevação estilística, advinda das fórmulas e vocábulos tradicionais do arcabouço épico. Isso tornava o dístico elegíaco elegante e de simples manipulação: qualquer grego minimamente instruído poderia compor nesse metro que, por esse motivo, a partir do século VII a.C., já se tornara o preferido para a composição de epigramas, isto é, inscrições votivas, funerárias ou dedicatórias (Fowler, 1987, p. 98). Não é difícil inferir que estas mesmas concisão e elevação da linguagem que o dístico facultava ao epigrama também encorajaram a composição de poemas de tom sentencioso e aforismático. De fato, muitos poetas se serviram dele para transmitir ensinamentos de modo memorável. Assim é que, concomitantemente aos epigramas, surgira outro gênero bem difundido na Grécia arcaica a empregar o dístico elegíaco: a elegia.

Embora elegia e epigrama compartilhassem o metro, havia uma distinção significativa entre eles, pelo menos até o séc. VI a.C. Enquanto o epigrama destinava-se às inscrições sobre um objeto - um túmulo ou uma oferenda a uma deidade -, a elegia é essencialmente um discurso em dísticos elegíacos, acompanhada musicalmente pelo aulo, instrumento de sopro similar ao oboé, e marcada por uma $1^{\text {a }}$ pessoa que se dirige a um destinatário específico em ocasião de performance determinada (West, 1974, p.1-2). Em um universo anterior à maior difusão da escrita, em que a circulação de versos se dava estritamente em performance, reconhecer a ocasião desta é fundamental para nos dar indícios da conformação de um poema a um gênero e um contexto específicos.

Hoje consolidou-se o pensamento de que a elegia tinha no simpósio sua principal, senão única, ocasião de performance. Talvez a mais difundida e influente instituição a se desenvolver no mundo grego arcaico (séc. VII-V

Filosofia e Educação [RFE] - Volume 9, Número 1 - Campinas, SP Fevereiro-Maio de 2017 - ISSN 1984-9605 - p. 45-62 
a.C.), o simpósio era uma reunião altamente ritualizada, exclusivamente composta por homens aristocratas ${ }^{3}$ de igual estatuto social. Começando depois do banquete, nele privilegiava-se o consumo do vinho e a recitação de discursos e canções que abarcavam desde a esfera política até incursões ao mundo de Eros (Rossi, 1983, p. 44). Como espaço ritualizado, o simpósio também permitia celebrar e idealizar valores ético-morais compartilhados pelos convivas (Vetta, 1995, p. 1xi). As definiçõos desse evento apresentam essencialmente a prescrição de um èthos, constituindo-se, portanto, o simpósio como um espaço para a exibição de educação, cultura, e valores aristocráticos, bem como para a sua transmissão (Vetta, 1992, p. 178).

De um lado, a elegia com sua simplicidade rítmica, concisão, clareza e tendência para um tom sentencioso; de outro, o simpósio enquanto espaço para transmissão de valores éticos, políticos e sociais: a conjugação dessas características responde à nossa aparente estranheza inicial perante uma "elegia educativa": a elegia grega arcaica, como sói à poesia antiga, instruía e deleitava, e o simpósio era cenário propício a ambas as atividades. Teógnis, entre outros poetas, encareceu a elegia como meio de oferecer à audiência preceitos éticos e políticos, como veremos em excertos de uma obra cujos numerosos versos conservados refletem uma poesia quase que exclusivamente voltada à paideia. Tais excertos serão, pois, guia exemplar para compreender a indissociável ligação entre elegia, simpósio e paideia.

\section{Teógnis, Cirno, elegia e paideia simposial arcaica}

Com Teógnis encontramos um caso distinto no que tange à preservação da obra: se para os demais poetas elegíacos contamos com corpora fragmentários e exíguos, dele diversos manuscritos conservam, sob seu

\footnotetext{
${ }^{3}$ Entende-se aristocracia conforme a define Sacks (2005, p. 45): “[...] forma antiga de governo em algumas cidades gregas, em que o poder era partilhado por um pequeno círculo cujos membros eram definidos pelo privilégio de um nascimento nobre".
}

Filosofia e Educação [RFE] - Volume 9, Número 1 - Campinas, SP

Fevereiro-Maio de 2017 - ISSN 1984-9605 - p. 45-62 
nome, cerca de 1400 versos elegíacos em bom estado, na chamada

Teognideia. Nem todos, porém, lhe pertencem: diversos seguramente são de outros poetas que viveram antes ou depois de Teógnis; e alguns sugerem datas tão distantes uma das outras que não poderiam ser reunidas no tempo de uma vida. O que os versos da Teognideia teriam em comum entre si é a composição para performance nos simpósios. É uma coleção que parecia auxiliar a récita de poesia no simpósio, bem como celebrar um programa poético adequado ao evento. Uma das elegias que abre a Teognideia institui um programa poético que projeta o simpósio como espaço ideal para a educação dos valores aristocráticos (versos 27-38):

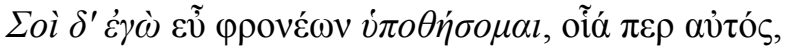

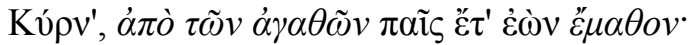

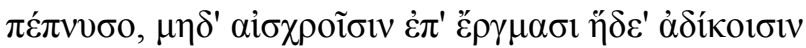

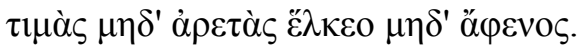

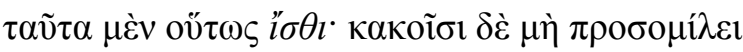

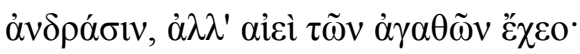

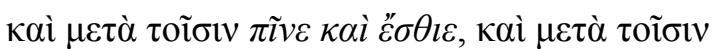

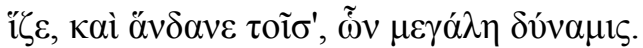

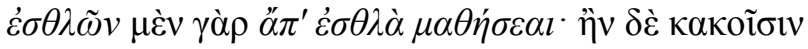

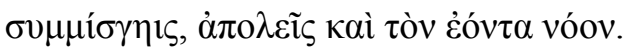

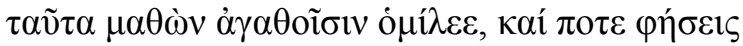

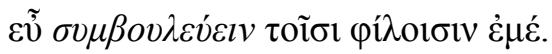

A ti eu aconselharei benévolo, como eu mesmo, Cirno, aprendi de bons homens ainda menino. Age com prudência, e por atos torpes ou injustos não te apropries de glória, mérito ou riqueza. 
Assim, aprende o seguinte: não busques a companhia de homens vis, mas apega-te sempre aos de valor.

Entre eles, come e bebe, e entre eles te assenta, agrada àqueles cujo poder é enorme.

De nobres, aprenderás o que é nobre: mas, se aos vis te misturares, até a tua razão perderás;

ciente disso, reúne-te aos bons, e um dia dirás que aconselho bem os meus amigos.

Esses versos, não por acaso, vêm logo após a elegia em que Teógnis anuncia a si mesmo ${ }^{4}$ : depois de se apresentar, ele se ocupa de descrever os propósitos de sua poesia e, por esse motivo, os excertos acima foram considerados programáticos 5 . De fato, os versos 27-38 resumem o conteúdo paidêutico que permeia a maior parte da obra de Teógnis e que lhe deu fama na Antiguidade. A enciclopédia Suda (século X d.C.) assim define o poeta no verbete que lhe dedica: "Compôs uma coleção de ensinamentos em versos elegíacos, para seu amado Cirno". Muitos séculos antes, Platão (Mênon, 95 c-d) evoca seu nome e cita os versos 33-36 para mostrar que Teógnis julgava a virtude (aretē) como passível de ser ensinada. As primeiras palavras do verso 27, soi ("para ti") e ego ("eu”), são apropriadas à perspectiva do gênero elegíaco: não lhe é próprio remeter ao passado longínquo, mas delimitar sua matéria ao momento presente e assim colocar em primeiro plano sua audiência. O "Eu" poético Teógnis, distinto do narrador épico (Canevaro, 2014, p. 29), não é voz distanciada que se confunde à da tradição. Teógnis se revela nas circunstâncias do presente, e adota deliberadamente a persona de um preceptor.

\footnotetext{
${ }^{4}$ Os versos 19 a 26, conhecidos como a "Elegia do Selo".

${ }^{5}$ Colesanti (2011, p. 310) chama-a de "manifesto programático", e Rösler (2006, p. 64), defendendo seu lugar na coleção, argumenta a favor do caráter proemial dessa elegia.
} 
Convém observar como este "Eu elegíaco" constrói sua figura: ele não colhe seus ensinamentos das Musas, deusas responsáveis pela palavra poética e avatares da tradição, mas os extrai dos ensinamentos que, por sua vez, recebera de outros nobres quando menino (v. 28). A educação transmitida de pai para filho, de nobre para nobre: verifica-se aí a importância que Teógnis dá à ascendência aristocrática. A virtude (aretē) é para ele uma prerrogativa da nobreza, e como tal, apenas pode ser ensinada no seio da aristocracia. Um poema da Teognideia mostra que é o nascimento que determina se um indivíduo será capaz ou não de aprender a virtude. Se nasce nobre (agathos), é possível lhe passar pensamentos nobres (phrenas esthlas); se não, estará para sempre condenado a ser vil (kakos) (vv. 429431).

A companhia de "bons homens" (agathoi) para produzir uma boa juventude revela-se um dos princípios da paideia grega arcaica (Levine, 1985, p. 178). O que garante a validade das admoestações políticas, civis e até mesmo eróticas de Teógnis não são as Musas, mas os valores tradicionais que enformam a vida aristocrática, passados de geração para geração, e que têm no simpósio o principal local de transmissão, uma vez que este é caracterizado, justamente, como espaço de reunião da nobreza.

O pronome de $2^{\mathrm{a}}$ pessoa (soi, “a ti”) no verso 27 também é importante, mostra sua posição no verso, que produz de maneira clara a presentificação da audiência e ao mesmo tempo singulariza o interlocutor, estabelecendo forte separação entre ele e o "Eu" que pronuncia os versos. Como resultado, cria-se uma hierarquização retoricamente eficaz ente "tu" e "Eu", muito frequente na literatura de cunho sapiencial e característica fundamental da poesia didática desde as suas origens orientais, em obras como a suméria Instruções de Surupakk, Conselhos de um pai para o desacertado filho e a egípcia Instruções de um homem ao seu filho (Canevaro, 2014, p. 30). São 
exemplos que mostram como Teógnis ampara-se nesta tradição, dela se distanciando, pois enquanto elas registram precipuamente os conselhos de um pai para um filho, a Teognideia situa seus aprendizados na atmosfera simposiástica de divertimento e convivialidade aristocrática (versos 31-32). Note-se que o receptor destes ensinamentos, o "tu" ao qual o "Eu elegíaco" se dirige, é bem delimitado, e atende por nome próprio: Cirno (v. 28).

No espaço aberto pela ficção poética, não convém perscrutarmos se Cirno existiu ou não como figura histórica, mas as ressonâncias que este nome produz são interessantes: estudiosos antigos viram em Cirno o amado (erōmenos) de Teógnis. Para além da mera intenção biografista, essa relação se vincula à própria concepção de paideia arcaica aqui comentada: em uma sociedade em que os mundos masculino e feminino viviam cindidos e as relações sexuais com mulheres eram vistas como meio de procriação ou apenas satisfação física, era natural que a iniciação sexual de um jovem fosse feita por um homem mais velho, pertencente aos mesmos círculos aristocráticos que ele. Este aristocrata assumia o papel de amador (erastēs) e também se incumbia da educação do amado (erōmenos) nos códigos morais e políticos que norteavam a aristocracia. A relação entre Cirno e "Teógnis" proposta por biógrafos antigos nada mais do que particularizaria e reduziria a uma dimensão interpessoal aquilo que é eminente na Teognideia: certos conselhos de conduta e preceitos que deveriam ser aprendidos para a vida política e aristocrática equiparam-se aos que o amador exige de seu amado: a pistis ("lealdade"), a kharis ("reciprocidade") e a dike ("equilíbrio").

No entanto, o personagem Cirno é exclusivamente destinatário de poemas de fundo político ou paidêutico. Poemas eróticos, uma seção à parte na Teognideia, nunca o têm como interlocutor. Essa constatação levantou a suspeita, já entre os antigos, de que Cirno não fosse uma figura histórica, 
mas antes uma ficção deliberadamente engendrada pelo poeta, e que usar o seu nome poderia ter um sentido específico em versos de conteúdo didático.

Fato é que a atribuição de um "Eu elegíaco" bem marcado que até se nomeia, e a criação de um interlocutor genérico, que possa servir de receptáculo para todo o tipo de ensinamento político e aristocrático, circunscreve a paideia a um âmbito poético: tudo se resolve nos limites da poesia que dissemina os preceitos políticos e éticos para a vida na pólis. Com isso, revela-se uma característica central da poesia didática: emoldurar narrativas para transmitir conteúdo sapiencial (Edmunds, 1997, p. 44). Na ficção do amador Teógnis e do amante Cirno, questiona-se aos ouvintes implicitamente qual o potencial de cada um: nobres, se compreendem e apreciam a poesia de Teógnis; vis, se falham. Assim, a elegia demonstra o quanto poesia e paideia são inseparáveis entre os gregos arcaicos, e como o simpósio revela-se um espaço para a performance de ambas. Mas a poesia não circulava unicamente em âmbito simposial. Uma boa parcela das produções poéticas classificadas como "líricas" se davam também fora dele, nos festivais públicos da cidade. O modo como se articulava a relação entre poesia e paideia nesse contexto é o que nos ocupará a seguir.

\section{A mélica - a lírica propriamente dita ${ }^{6}$}

Passemos ao outro gênero contemplado neste artigo: a mélica, nome menos usual, embora mais preciso, para a lírica, este prevalente sobretudo a partir da edição dos poetas na Biblioteca de Alexandria, notavelmente por Aristófanes de Bizâncio (c. 258-180 a.C.). Ambas as nomenclaturas guardam a ideia-chave da definição do gênero: canção para performance com acompanhamento da lira - daí lírica (ou lyrikēe $)^{7}$, que vem a substituir

\footnotetext{
${ }^{6}$ Essa etapa tem por base Ragusa (2010, p. 23-97; 2013, p. 11-35).

${ }^{7} \mathrm{Na}$ acepção moderna, muito usada, mas imprecisa, o termo designa todos os gêneros poéticos não-hexamétricos e não-dramáticos da Grécia antiga.
} 
outros mais antigos, com destaque para melos (canção), que origina o termo mélica (ou melikē) e que está presente no léxico musical de nossa língua.

$\mathrm{Na}$ Grécia arcaica, em que a oralidade sobrepuja a escrita, estamos no que se designa song culture (Herington, 1985, p. 3); nela, a poesia é "o veículo principal à disseminação de ideias morais, políticas e sociais" (id., $i b$.) - poesia esta que é eminentemente discurso composto segundo práticas tradicionais nos diferentes gêneros, plenamente inserida na vida da pólis e, portanto, pragmática, articulada a certo contexto e modo de performance (Rösler, 1985, p. 139). Isso se faz particularmente nítido em alguns gêneros poéticos, em especial na mélica, cuja natureza a plasma "em contexto ritual e performativo" (Swift, 2010, p. 14), realizado pela e para a comunidade da pólis, e cujas espécies (eidē) têm um papel, uma função "no mundo externo ao poema" (id., p. 15).

Ainda que se deva ressaltar que a definição de um gênero de poesia arcaica, inserido em cultura oral, deva ser encarada como flexível (Carey, 2009, p. 22), fato é que os tipos de mélica estão estreitamente articulados à performance à qual se destinam; "e é o papel que a ocasião [de performance] desempenha na comunidade que dá forma à natureza da poesia e às reações da audiência a ela" (Swift, 2010, p. 34).

Muito distinto deste era o cenário à época da edição da mélica em Alexandria. Lá, debruçados sobre as composições no gênero, os eruditos pareciam interessados "exclusivamente nas palavras dos poetas" (Most, 1982, p. 78) cujas canções se tinham transformado em textos para leitura, comentário e cópia, despidos da lira tornada antiga (e fugidia) recordação na nova nomenclatura (lírica) - ou seja, despidos de sua natureza oral, performática, pragmática. Retornando, pois, ao mundo da mélica arcaica, falemos de características pertinentes ao tema da paideia no gênero. 
Há para a mélica duas modalidades de performance: solo, com acompanhamento da lira, e coral, com a soma de diversos instrumentos à dança. Esta configura a molpē, a canção na sua "unidade de canto, dança e música" (Webster, 1970, p. xiii), dimensões de responsabilidade do poeta ${ }^{8}$. Ambas as modalidades têm traços característicos. A canção solo tem estruturas métricas antes estrofadas do que lineares, e menos complexas e longas do que as estruturas estróficas da canção coral. Aquela tem variedade temática e de tratamento da linguagem, enquanto esta tem na narrativa mítica, na autodramatização da performance e autorreferencialidade do coro, bem como na linguagem celebrativa, suas linhas de força. A mélica solo se liga com frequência à contemporaneidade e temas correlacionados, projetando imediatismo (D'Alessio, 2004, p. 270), enquanto a coral eleva-se do presente, ao celebrar deuses e homens em tramas articuladas ao passado mítico e à tradição, que superam os limites do tempo. Aquela se destina mais amiúde aos simpósios, esta aos festivais públicos cívico-cultuais das poleis que os organizavam e patrocinavam. Trata-se de ocasião solene, cuja "tônica dominante" "é o prazer, humano e divino" (Herington, 1985, p. 6).

A canção solo, está claro, é entoada por uma voz, enquanto a coral demanda um coro. Façamos uma pausa: quem integrava os coros que podiam variar em número de 7 a 50 coreutas? Majoritariamente, membros socialmente integrados nas poleis, dado que pode dar uma ideia do impacto de canções feitas para as comunidades e por elas, de canções que constantemente se elaboram na conjunção entre o presente e o passado mítico, a tradição - a memória coletiva e os valores nela preservados. Isso é possível porque, na Grécia, "participar de performance coral ou contemplála desempenhavam um papel central na vida cultural e musical” (Swift, 2010, p. 1), delineando "os momentos mais significativos da vida de

${ }^{8}$ A música é a dimensão menos acessível a nós. A dança é atestada nas próprias canções que dela falam, e em fontes iconográficas (Webster, 1970, p. 1).

Filosofia e Educação [RFE] - Volume 9, Número 1 - Campinas, SP

Fevereiro-Maio de 2017 - ISSN 1984-9605 - p. 45-62 
indivíduos e da comunidade, de casamentos, a funerais, a celebrações religiosas cívicas" (id., p. 2). Daí que, desde cedo, homens e mulheres eram treinados para a atividade coral e tudo o que isso envolvia.

Vale dizer, tudo somado, que a mélica coral "tinha papel central na afirmação dos valores e da unidade da comunidade" (Segal, 1990, p. 165). Isso porque

tendia a ser cantada em celebrações formais que unificavam a cidade como um todo coerente ao reconhecer o benefício divino e a empresa humana, e servia socialmente a garantir a integração completa da cidade, distinguindo-a de outras. [...] Ademais, [...] enfatiza as relações entre homem e deus, ao observar rituais de culto por meio dos quais uma cidade homenageia seus deuses, ao honrar o sucesso humano extraordinário que só é alcançável através do favor divino, e ao testemunhar momentos de transição nas vidas de indivíduos, que só podem ser concluídos de modo exitoso pela graça dos deuses. (Most, 1982, p. 90-1).

Dado o tema da paideia grega, concentramo-nos na mélica coral, olhando para uma canção de inescapável dimensão formativa, a qual se vem somar à função precípua do canto: dar prazer, entreter, deleitar. Pois justamente nessa função que desarma os ânimos reside o impacto potencial de contribuir para a paideia do homem grego.

\section{Álcman, o Partênio, as virgens: coro e paideia ${ }^{9}$}

Preservado em papiro do século I d.C., o Partênio do Louvre ou simplesmente Partênio, em geral editado como o Fragmento 1 de Álcman (ativo em c. 620 a.C.) - poeta de uma Esparta distante da pólis estritamente

${ }^{9}$ Para a tradução, aqui citada, e comentário: Ragusa (2013, p. 39-53; ver também 2010, p. 101-207).

Filosofia e Educação [RFE] - Volume 9, Número 1 - Campinas, SP

Fevereiro-Maio de 2017 - ISSN 1984-9605 - p. 45-62 
militarista da era clássica, e afeita à atividade coral e a poetas e músicos estrangeiros -, é canção coral de 105 versos. Sua denominação, Partênio, define sua espécie mélica - canção para performance por coro de virgens (parthenoi). Sua composição traz três partes típicas: na primeira, cujo proêmio se perdeu, a narrativa mítica (1-35), pouco legível, vinculada à tradição local, cantando uma guerra entre heróis da linhagem dos Tindaridas - Tíndaro e Leda são os pais de Helena, Clitemnestra, e dos gêmeos Cástor e Polideuces; bem mais legíveis, a gnōmē ("sentença, máxima”, 36-9) de transição e a $2^{\mathrm{a}}$ parte, cujo tema é a autodramatização pelo coro de sua própria performance (39-105).

Seja qual for o relato mítico, seu quadro é noturno, sombrio, pois canta a morte e a destruição como frutos da inobservância dos limites inerentes à condição humana, válidos inclusive para os heróis - ou seja, por crimes de hybris (desmedida, excesso, violência, arrogância, pretensão, insolência), que repercutem no mundo dos deuses e ativam o mecanismo do equilíbrio pela retribuição punitiva $(\text { tisis })^{10}$. As admoestações da parte mítica não deixam dúvidas quanto a tal quadro:

\section{Versos 16-17 [ [ [

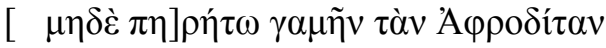 \\ que homem nenhum voe rumo ao céu, e nem pretenda desposar Afrodite}

Versos 34-9 [final da narrativa mítica e gnōmē, 36-9]

$$
[\ldots] \ddot{\alpha} \lambda \alpha \sigma \tau \alpha \delta \dot{\varepsilon}
$$

mas inesquecíveis

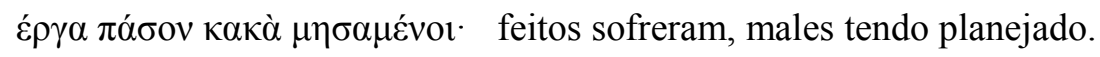

\footnotetext{
${ }^{10}$ Del Grande (1947, p. 1): hybris é "a 'insolência', a violência excessiva de quem, incapaz de pôr à sua ação um freio - produto do respeito do direito dos outros, da consciência do justo, da piedade -, ultrapassa [...] os limites do quanto seja correto, causando a injustiça", e ofendendo "diretamente os deuses, tutores da ordem social [...]".
} 


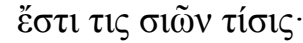

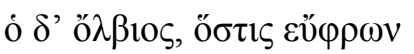

$\dot{\alpha} \mu \varepsilon \dot{\rho} \rho \alpha v[\delta 1] \alpha \pi \lambda \varepsilon ́ \kappa \varepsilon 1$

$\ddot{\alpha} \kappa \lambda \alpha v \tau \circ \varsigma \cdot[\ldots]$
Há algo como o castigo dos deuses;

feliz quem alegremente

o dia entretece até o fim,

sem pranto; [...]

Articulada aos versos 16-7 e 34-5, com suas admoestações quanto aos perigos de incorrer em hybris e a certeza da punição divina, a gnōmē (36-9) encerra verdades concretas, empiricamente provadas na experiência humana, para a qual os mitos - as narrativas tradicionais - funcionam como exemplos modelares, essenciais à mélica e caros à elegia, em que costumam ter "função moralizante" (Del Grande, 1947, p. 71). E os dizeres da gnōmē enfatizam sonoramente a punição (tisis): Esti tis siōn tisis ("Há algo como o castigo dos deuses", 36), canta a síntese da "significação moral" (Too, 1997, p. 9) da narrativa mítica, preparando a reflexão da gnōmē que conduzirá a canção ao presente da performance, em que parthenoi, as moças ainda não casadas $^{11}$, se apresentam à polis. Tal reflexão, ancorada no tempo presente, define quem é "feliz" - olbios, termo que nomeia a prosperidade material e imaterial, favorecida pelos deuses -, e o faz em linguagem concisa, ágil, de transições bruscas, típica da estilística poética arcaica, marcada pela oralidade. No canto das virgens, expressa-se a visão tradicional de que, ignorando o futuro, o homem mortal "deve se contentar com sua jornada diária, e a máxima felicidade que pode alcançar é transcorrer alegremente uma única jornada" (Pavese, 1992, p. 120-1) encarada como "momento fixo e conclusivo em si mesmo (e, sob esse aspecto, poder-se-ia dizer eterno)" (id., ib.).

Evidencia-se que a gnōmē dos versos 36-9 resume a conclusão éticomoral extraída da narrativa mítica, ou, por outra, nela revalida a verdade que

\footnotetext{
11 No imaginário grego, a virgindade não é pensada em termos de castidade pura e assexuada, mas de condição de meninas-moças situadas entre a infância e a idade adulta marcada pelo casamento que conclui a integração social da mulher (Sissa, 1990, p. 76).
}

Filosofia e Educação [RFE] - Volume 9, Número 1 - Campinas, SP

Fevereiro-Maio de 2017 - ISSN 1984-9605 - p. 45-62 
a experiência humana dá a conhecer, a ser lembrada, para que não incorram os mortais do presente no erro dos homens do passado, os heróis. O coro integrado pelas futuras esposas de Esparta, ao cantar essa gnōmē e mesmo ao pontuar com admoestações gnômicas o relato mítico (16-7, 34-5), revalida no presente valores tradicionais, compartilhados pela comunidade no correr dos tempos, notadamente, da reverência aos deuses e da importância da observância dos limites da condição mortal. Contrapondo o presente luminoso ao passado de violência e ruptura, as parthenoi desenham-se, em linguagem fortemente imagética e sugestiva, "como representantes de uma sociedade que demonstra ordem e respeito pela autoridade" (Too, 1997, p. 16). O coro assim exibe sólida formação éticomoral e firmes elos com a comunidade, algo importante numa apresentação que propicia às virgens a oportunidade de serem vistas como "potenciais e desejáveis parceiras de boda" (Ingalls, 2000, p. 6) ${ }^{12}$ pelos jovens aristocratas que as desposarão ${ }^{13}$. Mais do que exibir, o partênio de Álcman viabiliza tal formação e a sedimentação de tais elos, funcionando a canção do poeta e as demais dessa espécie mélica como "importantes instrumentos de paideia, um processo que inculcava responsabilidade cívica, valores sociais e tradições (...) codificados na performance, que servia [no caso específico dos partênios] para integrar o indivíduo do sexo feminino em seu contexto social" (Clark, 1996, p. 144).

\footnotetext{
${ }^{12}$ Isso se reflete na $2^{\mathrm{a}}$ parte da canção, introduzida pelo elogio pelo coro de uma de suas coreutas (Agidó). Daí em diante (39-105), desenrola-se a autodramatização da dança, do próprio canto e da figura graciosa das virgens.

${ }^{13}$ Ver Stehle (1997, p. 32). 


\section{Referências}

ADKINS, A. W. H. Poetic craft in the early Greek elegists. Chicago: The University of Chicago Press, 1985, 248p.

CAREY, C. Genre, occasion and performance. In: BUDELMANN, F. (ed.). The Cambridge Companion to Greek lyric. Cambridge: Cambridge University Press, 2009, p. 21-38.

CLARK, C. A. The gendering of the body in Alcman's Partheneion 1. Helios 23, p. 143-72, 1996.

COLESANTI, G. Questioni Teognidee. Roma: Edizioni di Storia e Letteratura, 2011, 380p.

D'ALESSIO, G. B. Past, future and present past: temporal deixis in Greek archaic lyric. Arethusa 37, p. 267-94, 2004.

DEL GRANDE, C. Hybris. Napoli: Riccardo Ricciardi Editore, 1947, 560p.

EDMUNDS, L. The seal of Theognis. In: ; WALLACE, R. W. (orgs.)

Poet, public, and performance in ancient Greece. Baltimore: Johns Hopkins University Press, 1997, p. 29-48.

FOWLER, R. L. The nature of early Greek lyric. Toronto: University of Toronto Press, 1987, 147p.

HERINGTON, J. Poetry into drama. Berkeley: University of California Press, 1985, 350p.

INGALLS, W. B. Ritual performance as training for daughters in archaic Greece. Phoenix 54, p. 1-20, 2000.

LEVINE, D. B. Symposium and the polis. In: FIGUEIRA, T. J; NAGY, G. (eds). Theognis of Megara. Baltimore: Johns Hopkins University Press, 1985, p. 176-196.

MOST, G. W. "Greek lyric poets”. In: LUCE, T. J. (ed.). Ancient writers - I. New York: 1982, p. 75-98.

NAGY, G. Theognis and Megara. In: FIGUEIRA, T. J; (eds). Theognis of

Megara. Baltimore: John Hopkins University Press. 1985, p. 29-85.

Filosofia e Educação [RFE] - Volume 9, Número 1 - Campinas, SP

Fevereiro-Maio de 2017 - ISSN 1984-9605 - p. 45-62 
$\overline{\text { PAVESE, C. O. (ed., coment.). Il grande Partenio di Alcmane. Amsterdam: Adolf }}$ M. Hakkert, 1992, 106p.

RAGUSA, G. Lira, mito e erotismo: Afrodite na poesia mélica grega arcaica. Campinas: Editora da Unicamp, 2010, 664p. (Apoio: Fapesp). (org., introd., trad., notas). Lira grega: antologia de poesia arcaica. São Paulo: Hedra, 2013, 290p.

RÖSLER, W. Persona reale o persona poetica? QUCC 19, 131-44, 1985. . "La raccolta di Teognide". In: ROSCALLA, F. (ed.) L'autore e l'opera: attribuzioni, appropriazioni, apocrifi nella Grecia antica. Pise: Ed. ETS, 2006, p. 5567.

ROSSI, L. E. "Il simposio arcaico e classico come spettacolo a se stesso". In: DOGLIO, F. (ed.). Spettacolo conviviali dall' antichità classica alle corti italiani del 400. Viterbo: Centro Italiano di Studi sull'Alto Medioevo, 1983, p. 41-50.

SACKS, D. Encyclopaedia of ancient Greek world. New York: Facts on File, 2005, $433 \mathrm{p}$.

SEGAL, C. "Archaic choral lyric". In: EASTERLING, P. E.; KNOX, B.W. (eds.). The Cambridge History of classical literature - I: Greek literature. Cambridge: Cambridge University Press, 1990, p. 165-201.

SISSA, G. Greek virginity. Trad. A. Goldhammer. Cambridge: Harvard University Press, 1990, 248p.

STEHLE, E. Performance and gender in ancient Greece. Princeton: Princeton University Press, 1997, 367p.

SWIFT, L. A. The hidden chorus. Echoes of genre in tragic lyric. Oxford: Oxford University Press, 2010, 472p.

TOO, Y. L. Alcman's Partheneion. QUCC 56, p. 7-29, 1997.

VETTA, M. Introduzione. In: ___ (ed.). Poesia e simposio nella Grecia antica. Bari: Laterza, 1995, p. xii-lx. . Il simposio. In: CAMBIANO, G. et al. (eds.). Lo spazio letterario della Grecia antica I. Roma: Salerno, 1992, p. 177-218.

Filosofia e Educação [RFE] - Volume 9, Número 1 - Campinas, SP Fevereiro-Maio de 2017 - ISSN 1984-9605 - p. 45-62 
WEBSTER, T. B. L. The Greek chorus. London: Methuen, 1970, 240p.

WEST, M. L. Studies in Greek elegy and iambus. Berlin: Walter de Gruyter, 1974, 198p.

Filosofia e Educação [RFE] - Volume 9, Número 1 - Campinas, SP Fevereiro-Maio de 2017 - ISSN 1984-9605 - p. 45-62 